\title{
BMJ Open Conflict-of-interest disclosure at medical journals in Japan: a nationwide survey of the practices of journal secretariats
}

\author{
Takako Kojima, ${ }^{1}$ Joseph Green, ${ }^{2}$ J Patrick Barron ${ }^{3}$
}

To cite: Kojima T, Green J, Barron JP. Conflict-of-interest disclosure at medical journals in Japan: a nationwide survey of the practices of journal secretariats. BMJ Open 2015;5:e007957. doi:10.1136/bmjopen-2015007957

- Prepublication history and additional material is available. To view please visit the journal (http://dx.doi.org/ 10.1136/bmjopen-2015007957).

\section{These findings were} presented in part at an invited JAMS symposium on February 28, 2014, and in a Letter to the Editor of Chest.

Received 13 February 2015 Revised 6 August 2015 Accepted 7 August 2015

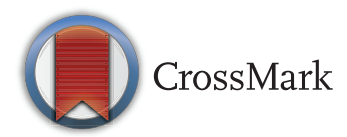

${ }^{1}$ Department of International Medical Communications, Tokyo Medical University, Tokyo, Japan

${ }^{2}$ Graduate School of Medicine, University of Tokyo, Tokyo, Japan

${ }^{3}$ Tokyo Medical University, Tokyo, Japan

\section{Correspondence to} Joseph Green; jgreen@m.u-tokyo.ac.jp

\section{ABSTRACT}

Objectives: Medical journals in Japan generally have appropriate policies regarding disclosure of conflicts of interest (COI). However, $\mathrm{COI}$ management depends on the staff members of each journal's editorial secretariat. This study's objectives were to find out $(\mathrm{A})$ whether $\mathrm{COI}$ disclosure and the journal's role in it are clearly understood by the journal's secretariat staff, (B) how much experience the editorial secretariat has in actually handling issues related to disclosure and (C) what kind of help or support they need.

Setting and design: In January 2014, questionnaires were sent to the editorial secretariats of journalpublishing societies belonging to the Japanese Association of Medical Sciences (JAMS).

Participants: The response rate was $100 \%$, and the respondents represented 121 journals published by the 118 JAMS member societies (at the time of the survey).

\section{Primary and secondary outcome measures:}

Information was collected on the history of $\mathrm{COI}$ policies and on how those policies were implemented. At the end of the questionnaire, there was an open-ended call for comments.

Results: Compulsory COI disclosure began between 2010 and 2013 for $60.3 \%$ of the journals (73/121). Handling of COI issues was not uniform: $17.4 \%$ (21/121) of respondents do not pursue cases of dubious disclosure, and $47.9 \%$ (58/121) do not require $\mathrm{COI}$ disclosures from editorial board members. Very few of the editorial secretariats had clearly-stated consequences for violations of COI-disclosure policy (33/121, 27.3\%), and only $28.9 \%$ offered COI education (35/121). Respondents' comments indicated that uniform, easily-searchable guidance regarding $\mathrm{COI}$ policies and implementation would be welcome.

Conclusions: Although commitment is widespread, policy implementation is inconsistent and COI experience is lacking. Clear, easy-to-use guidelines are desired by many societies. The JAMS is to be commended for supporting this country-wide investigation; other countries and regions are encouraged to perform similar investigations to respond to needs regarding $\mathrm{COI}$ management.

\section{Strengths and limitations of this study}

- This is the first-ever international report of a nationwide survey on conflicts of interest (COI) management among Japanese medical societies.

- The response rate was $100 \%$, and the respondents represented 121 journals published by the 118 member societies (as of the time of the survey, January 2014) of the Japanese Association of Medical Sciences (JAMS).

- The findings should not be generalised outside Japan, so additional nationwide surveys such as this one will be needed to facilitate obtaining a grasp not only of policies but also of actual COI-management practices in various countries and regions.

\section{INTRODUCTION}

In publishing medical research, conflicts of interest (COI) are 'almost inevitable'. ${ }^{1}$ Of course they should be disclosed, but research on COI disclosure indicates that journals' policies vary widely. ${ }^{2}$ Editors are interested in standardising disclosure, although doing so may be difficult. ${ }^{2}$ There is also some evidence that repeated auditing might improve COIdisclosure practices. ${ }^{3}$

Our focus was on the people who ensure that COI are disclosed. Editors and authors can avail themselves of training materials on publication ethics, ${ }^{4}$ and senior researchers are encouraged to teach good publication practices to their juniors. ${ }^{5}$ Anyone with an Internet connection can easily access clear statements of positions on this topic that have been endorsed by groups of journal editors. $^{6-8}$ Such education and official declarations are essential, but we suspect that they are insufficient, because policies on COI disclosure are implemented by the staff members of each journal's editorial secretariat. We believe that their role is crucial. They are a journal's first point of contact with authors who may have COI, and, also, 
at later stages of the submission and publication process, those staff members translate policies into practice.

To continue illuminating the realities of COI management, we began close to home. The Japanese Association of Medical Sciences (JAMS) is a group that comprised 118 academic medical societies ${ }^{9}$ at the time of the survey, January 2014. The member societies publish journals with original research in basic medical sciences, clinical medicine, laboratory medicine, public health, etc. The COI Subcommittee of the JAMS requested one of its members (one of the authors, JPB) to report on COI management by JAMS member societies. The official guidelines of the JAMS with regard to COI disclosure ${ }^{10}$ are generally consistent with the positions of the International Committee of Medical Journal Editors (ICMJE), the World Association of Medical Editors (WAME) and the Council of Science Editors (CSE), but we were interested in the implementation of those policies at each journal's editorial secretariat. Here we report information provided by the JAMS member societies with regard to (A) whether there is a clear understanding of COI disclosure and of the journal's role, (B) how much experience the editorial secretariat has in actually handling issues related to disclosure and $(\mathrm{C})$ what kind of help or support they need. ${ }^{11}$

\section{MATERIALS AND METHODS}

We compiled a list of eight questions. All authors contributed ideas as to what questions to ask, based on a total of more than 80 person-years of experience in medical editing and publishing. As a native speaker of Japanese, one of the authors (TK) revised and edited the questions for language suitability. One question was added by the JAMS office. The questions concerned the history of COI policies of each journal, and how those policies were implemented. After completion of the list, there was an open-ended call for comments on the topic.

The questionnaire was distributed in January 2014 by the JAMS central office to editorial secretariats of its 118 bunkakai, which are its member societies, all of which publish journals. Other bunkakai were added to the JAMS after this survey was completed. As of 17 May 2015, 5 bunkakai had been added, making a total of 123. ${ }^{12}$ The completed forms were returned to the JAMS office, which then collected and sent them to one of the authors (JPB), who was responsible for collating and tabulating the data.

\section{RESULTS}

All 118 bunkakai returned their forms. A total of 121 forms were returned, because 3 of the bunkakai returned 2 forms each, 1 for their Japanese-language journal and 1 for their English-language journal. For each of those 3 bunkakai, it is clear that the 2 journals had separate editorial secretariats, because the contact information and the responses to the questions were different. Thus it was clear that there was no duplication of respondents.
Because of missing data on some questions, the tabulated responses reported here sum to less than $100 \%$ (box 1).

The first question asked if the journals made any efforts to positively corroborate the credibility of COI disclosures, especially when the authors of a paper stated that they had no COI to declare. Approximately $77 \%$ of the societies do not make any effort to corroborate statements regarding the absence of COI, and only $19.8 \%$ stated that they did attempt to confirm COI statements.

In response to the next question, $42.9 \%$ of the journals stated that they do not check with the author in cases where the COI disclosure statement is incomplete. More than $75 \%$ of journals either had no such clarification issues, or had fewer than four cases per year.

Regarding the period in which societies began to require COI disclosure, there was a clear peak $(60.3 \%)$ in the 4-year period of 2010-2013. When asked about investigations of dubious cases of COI declaration, almost $70 \%$ stated that they did investigate suspicious cases but $21(17.5 \%)$ of the respondents revealed that they did not (about 13\% did not respond to this question). Comments made by the societies concerning this aspect included statements suggesting that their investigational system had not been fully determined and that the societies consider themselves to be in a kind of trial period. There were also some comments indicating that while some journal secretariats believe such matters to be in the province of the COI committee, others consider it is not the duty of the editorial committee to act on such issues. There was also a comment from a single journal that a suspicious case would be discussed with the publisher. That 'publisher' referred to a company that, we suspect, might not respond as a scholarly society would to cases of undisclosed COI.

In response to the question on whether editorial board members are asked to disclose any personal COI on their appointment as board members, almost half $(47.9 \%)$ stated that they do not make such disclosure obligatory. Those journals that did make it obligatory constituted just under half $(49.6 \%)$ of the total number of journals, suggesting that journals may not be aware that all persons related to the publication of the paper, including authors, reviewers, medical editors and all those named in the Acknowledgement section, should disclose any potential COI.

One question was a composite, inquiring whether the reviewers and the editorial board members understood the significance and importance of COI disclosure, and also whether the society carried out any education or training regarding COI disclosure. From the responses to this question, we found that $\mathrm{COI}$ education was given by only 35 of the editorial secretariats (28.9\%). With regard to sanctions or obligations imposed on those who contravene COI disclosure policy, such as enforced retraction, embargoes on paper submission, etc, only $27.3 \%$ of journals had a regulation system in place. 
Box 1 English versions of the questions included in the conflicts of interest (COI) questionnaire, and tabulated responses

Question 1: Has your journal made any effort to positively prove the credibility of COI disclosure or declaration (especially when "No COI to declare" is reported)? How do you corroborate this statement?

Yes: $24(19.8 \%)$

No: 93 (76.9\%)

No response: $4(3.3 \%)$

Question 2: In your journal, if the COI disclosure by the author has not been made or is incomplete at submission, does the secretariat request an explanation? If yes, how many times a year?

Yes: $63(51.7 \%)$

Up to $3: 41(33.8 \%)$

4-10: $12(9.9 \%)$

11-25: 5 (4.1\%)

26 and over: $5(4.1 \%)$

No: $52(42.9 \%)$

No response: $6(5.0 \%)$

Question 3: When did you start posting the requirement for COI disclosure in the Instructions to Authors of your journal?

2005-2009: $26(21.5 \%)$

2010-2013: $73(60.3 \%)$

2014-: $9(7.4 \%)$

1 responded "from 2001 "

No response: $13(10.7 \%)$

Question 4: Does your journal investigate when dubious cases regarding COI declaration arise?

Yes: $84(69.4 \%)$

No: $21(17.5 \%)$

No response: $4(3.3 \%)$

Other: 12 (9.9\%), for example, have not had any dubious cases so far; will consider the investigational system after rules have been implemented; Editorial Committee and COI Committee will decide if it occurs

Question 5: Do you make it obligatory for members of the editorial committee of your journal to make col disclosures when they are appointed?

Obligatory: $60(49.6 \%)$

Not obligatory: $58(47.9 \%)$

No response: $3(2.5 \%)$

Question 6: Do the reviewers and editorial board members understand the significance and importance of COI disclosure? What kind of edu-

cation or training do you carry out to ensure the above?

Education given: $35(28.9 \%)$

No education given: $82(67.8 \%)$

No response: $4(3.3 \%)$

Question 7: Do you have a system of regulations for sanctions regarding those who contravene COI disclosure policy? (Paper withdrawal, embargo on paper submission etc.)

Regulation system in place: $33(27.3 \%)$

No sanction system: $85(70.2 \%)$

No response: $3(2.5 \%)$

Question 8: How often per annum does your office receive questions about COI and COI disclosure?

1-5: $42(34.7 \%)$

10-30: $8(6.6 \%)$

None: $53(43.8 \%)$

'Almost none' or no response: $18(14.9 \%)$

Question 9: Please list any problems or unclear points concerning COI management regarding submitted manuscripts (see online supplementary appendix).

In response to our request for comments regarding COI management and related problems, it became clear that some journals had not experienced a single case of COI disclosure problems. An overall lack of confidence in the suitability of their own system was expressed in comments by many journals. There were also repeated comments on the lack of a sufficient surveillance mechanism and systems that would allow for reliable and transparent implementation of COI management.
Questions were also raised by editorial secretariats concerning present policies of holding documentation for only 1-2 years after publication of a paper. The feeling was also expressed that, since university and research institutes usually have ethics committees, regulation of researchers' ethical behaviour should be left up to the authors themselves, or their institutions, and should not be the responsibility of the journal or the editorial secretariats. 
In general, the comments highlighted a lack of a uniform system of COI management implementation and the need for more convenient and easy-to-refer-to guidelines in Japanese for the use of the journals' secretariats.

\section{DISCUSSION}

We set out to determine how COI-disclosure policies were being implemented at medical journal-publishing societies in Japan. Only half of the journals requested an explanation if a COI-disclosure statement was missing or incomplete, which shows that having a policy is insufficient, as implementation can be lacking or inconsistent.

More than $15 \%$ of journals in Japan in our study did not investigate cases in which non-disclosure of COI was suspected, which threatens the viability of the entire system. This could be a cause and an effect of the current situation in Japan, in which many staff members at editorial secretariats lack confidence in implementing COI-related policies, although they are given those responsibilities. Staff members of editorial secretariats were uncertain about the implementation of COI-disclosure policies at their journals. In addition, practices such as sanctioning violators of journal policy, COI disclosure by editors and reviewers, and education about COI were implemented inconsistently among the journals.

As pointed out by Smith in his 1998 BMJ editorial and reaffirmed by Irwin in his comments 11 years later, expectations for transparency and accountability of research are increasing, so COI needs constant attention, and this appears to be a common worldwide situation. ${ }^{5} 13$ This was particularly highlighted in the findings by Alfonso et al. ${ }^{2}$ In a randomised trial, "BMJ readers reported that data showing the impact of pain from herpes were less interesting, important, relevant, valid and believable when the authors were employees of a fictitious pharmaceutical company compared with an ambulatory care centre." ${ }^{14}$ This indicates that the task of those who educate authors and implement COI-related policies is complicated further because of the belief that readers will discount the results of a study if the authors of that study had a potential COI. That belief is justified. ${ }^{14}$

Although some of the societies in this survey consider that COI education and policy implementation is the province of universities and research institutes, we would submit that the societies or journals themselves are the ultimate gatekeepers of scientific integrity. Journals and academic societies are thus obligated to educate their officers and members concerning COI and COI disclosure. As necessary as it is, education concerning COI does have its challenges, which agrees with the findings of Alfonso $e t a l^{2}$ Therefore, creating uniform guidelines on COI that can be easily used, regardless of the level of awareness the author has, could provide a solution to this problem. Regarding this, many international journals and institutions, such as the BMJ and AMA, have sought to explain how to deal with COI problems in an open, fair and transparent manner.

Attitudes towards COI have become stricter and definitions are receiving more attention worldwide. In Japan, journal-publishing medical societies first adopted COI policies around 2010; the ICMJE had recently, in 2009, introduced its COI Disclosure Form. Several modifications of the latter were made based on feedback regarding the form, after piloting it and making it publicly accessible among ICMJE member journals. ${ }^{15}$ Modifications included elimination of the necessity of including authors' spouses, minor dependents, relatives and nonfinancial COI. ${ }^{16}$ However, many Japanese societies and journals still specify that these be included in COI disclosures. This situation emphasises the need for authors to consult Instructions to Authors before submission, but even more importantly, it suggests the need for at least national, if not international, policies in all fields of medical research.

Approximately half of all society journals in this study do not require their editorial board members to make COI disclosures, and thus they contravene the ICMJE Recommendations, which state that all those involved in the publishing process should disclose any potential COI. ${ }^{17}$ Journals might protect their credibility by applying such recommendations not only to staff members who make day-to-day decisions, but also to the editorial advisory board, as the latter's guidance on matters of a journal's focus, direction and priorities could be adversely affected by COI. Furthermore, not only authors, but reviewers and editors, and all editorial secretariat members, as well as anyone mentioned in Acknowledgement sections, should be given education on the significance of COI and on how to make appropriate, transparent statements. In addition, it may be advisable for journals to provide detailed information on COI, separate from the Instructions to Authors, perhaps preceding the COI disclosure forms, clearly specifying the nature of the situation and requiring individual agreement from all coauthors, before consideration for publication. The results of our survey point to a lamentable lack of education in this field, which, given the coverage and response rate of the present survey, likely involves nearly all of medical publishing in Japan, and which we suspect is a problem facing many other countries as well.

Regardless of whether non-disclosure of COI is intentional or an honest mistake, authors, as members of the scientific community, cannot plead ignorance of the rules. But authors are in a difficult situation, because the understanding of what constitutes COI can itself differ among individuals, institutions and countries. Furthermore, editors are in a difficult position as well, as the time and resources they can devote to handling ethical issues are limited. ${ }^{2}$ Also complicating the situation is the fact that editors have a variety of opinions on COI management. For example, arduous though the 
task may be, perhaps editors of medical journals worldwide could strive to find areas of consensus regarding responses to violations of COI-disclosure policies.

In this regard, and with a mind to the desirability of uniformity and international harmonisation of policies, it may be necessary to strengthen and increase recognition of organisations such as the Committee on Publication Ethics (COPE), as the study by Graf $e t a l^{3}$ points out that even some editors of COPE member journals are unaware of the COPE. In particular, the COPE has produced flowcharts that are freely available in several languages, providing advice and steps to follow for journals in cases of suspected or definite undisclosed COI. ${ }^{18}$ They also make it clear to authors what process will be followed in such cases. National bodies such as the JAMS could also play an important role.

\section{Limitations}

We could not be sure whether the respondent to a given questionnaire was a staff member working in the editorial office, or the editor, or a representative of the COI committee for that society, and respondents in different positions could differ in their understanding of COI-related issues and in their experience implementing COI policies. This limitation emphasises the need for an easily comprehensible transparent system of guidelines and procedures consistently evaluable by all staff. The strongly hierarchical nature of the Japanese medical world may prevent editorial-secretariat staff from contributing fully to the development and implementation of processes for managing COI-related issues, and that would also be true in similarly hierarchical workplaces worldwide.

Despite the increasing concern regarding various aspects of COI, Japanese medical societies (and, we suspect, academic societies in many other nations) lack uniform understanding, despite great sincerity and effort, and are also lacking in many aspects of COI education. The confusion in the editorial offices of Japanese medical societies about COI management clearly shows that greater and more thorough emphasis should be placed on education in scientific communications ethics.

\section{Conclusion}

On the basis of these findings, we recommend that Japanese medical societies adopt common guidelines on how to manage COI. Furthermore, providing a form such as the ICMJE COI form (at least until a more widely accepted form is developed) in Japanese to all Japanese medical societies could help their editorial secretariats standardise their education for staff, reviewers and editors. A Japanese translation of the form is freely available, together with explanations in Japanese of the issues it addresses. ${ }^{19}$ The AMA, among other societies, now requires that all authors submitting to JAMA submit the ICMJE COI Disclosure Form, ${ }^{20}$ and the JAMS member societies too would do well to require such a document. However, we also believe that COI disclosure should include all interests that might affect the perception of the behaviour of the author(s), and therefore should include non-financial COI. Hamilton states that personal COI, such as COI with a family member, religious, cultural, ethnic, or political COI, are potentially as detrimental as financial COI. ${ }^{4}$ Therefore, we recommend that a standard form be developed in Japanese for non-financial COI.

Creating simple guidelines on COI disclosure and management in Japanese can help the staff of editorial secretariats enforce their journals' policies. We recommend that the JAMS societies use a standardised Japanese-language COI disclosure form, to help authors as well as editorial offices understand clearly what information they should disclose when submitting a paper to any member journal of the JAMS. The measures outlined here could also enable focused education on COI, and improve the overall situation of COI management.

In closing, we note that diversity such as we found in Japan has also been seen in some Western countries. ${ }^{23}$ Still, without comparable studies of practices at journal secretariats in other parts of the world, the status of COI management globally remains unclear. We hope that others will follow the JAMS example of honest selfexamination of the translation of policy into practice.

Acknowledgements The authors thank the JAMS COI Subcommittee Chair, Professor Saburo Sone, and Mr Hidenori Takahashi of the JAMS Secretariat, for distributing our questionnaire; Dr Fumimaro Takaku, President of the JAMS, for facilitating the COI symposium; and Ms Sae Nakano and Ms Kaori Hijikata, remunerated personal assistants of one of the authors (JPB), for compiling and tabulating the responses.

Contributors The questionnaire was composed by all the authors (TK, JG, JPB). Tabulation of the data was the responsibility of JPB. The manuscript was written collaboratively by TK, JG and JPB. All the authors agreed to submission.

Competing interests None declared.

Provenance and peer review Not commissioned; externally peer reviewed.

Data sharing statement All authors, external and internal, had full access to all of the data (including statistical reports and tables) in the study and can take responsibility for the integrity of the data and the accuracy of the data analysis.

Open Access This is an Open Access article distributed in accordance with the Creative Commons Attribution Non Commercial (CC BY-NC 4.0) license, which permits others to distribute, remix, adapt, build upon this work noncommercially, and license their derivative works on different terms, provided the original work is properly cited and the use is non-commercial. See: http:// creativecommons.org/licenses/by-nc/4.0/

\section{REFERENCES}

1. British Medical Journal. Declaration of competing interests. http:// www.bmj.com/about-bmj/resources-authors/forms-policies-andchecklists/declaration-competing-interests (accessed 6 Aug 2015).

2. Alfonso F, Timmis A, Pinto FJ, et al., Editors' Network European Society of Cardiology Task Force. Conflict of interest policies and disclosure requirements among European Society of Cardiology National Cardiovascular Journals. Heart 2012;98:e1-7.

3. Graf C, Meadows A, Stevens A, et al. Ethics in Practice: Improvements in Ethical Policies and Practices in Wiley Health Science Journals Following a 2-Stage Audit Cycle. Abstract presented at the Seventh International Congress on Peer Review and Biomedical Publication; 8-10 September 2013, Chicago, IL. http://www. peerreviewcongress.org/abstracts_2013.html (accessed 6 Aug 2015). 
4. Hamilton CW. Essential ethics for medical communicators (an Essential Skills Workshop of the American Medical Writers Association). American Medical Writers Association, 2011: 27-31.

5. Irwin RS. The role of conflict of interest in reporting of scientific information. Chest 2009;136:253-9.

6. International Committee of Medical Journal Editors. Recommendations for the Conduct, Reporting, Editing and Publication of Scholarly Work in Medical Journals. Author Responsibilities-Conflicts of Interest. http://www.icmje.org/ recommendations/ (accessed 6 Aug 2015).

7. The World Association of Medical Editors. WAME Editorial on COI. http://www.wame.org/about/wame-editorial-on-coi (accessed 6 Aug 2015).

8. The Council of Science Editors. Editor Roles and Responsibilities. http://www.councilscienceeditors.org/resource-library/editorialpolicies/white-paper-on-publication-ethics/ (accessed 6 Aug 2015).

9. The Japanese Association of Medical Sciences. Seminar on COI Management. http://jams.med.or.jp/coi/coi_seminar_07.html (accessed 6 Aug 2015).

10. The Japanese Association of Medical Sciences. Guidelines on COI Management. http://jams.med.or.jp/guideline/coi-management 201402.pdf (accessed 6 Aug 2015)

11. Kojima T, Green J, Barron JP. How Japanese medical journals manage conflicts of interest. Chest 2015;147:e60.
12. The Japanese Association of Medical Sciences. http://jams.med.or jp/en/ms.html (accessed 15 May 2015).

13. Smith R. Beyond conflict of interest. Transparency is the key. BMJ 1998;317:291-2.

14. Chaudhry S, Schroter S, Smith R, et al. Does declaration of competing interests affect readers' perceptions? A randomized trial. BMJ 2002;325:1391-2.

15. International Committee of Medical Journal Editors. Uniform Requirements for Manuscripts Submitted to Biomedical Journals. http://www.icmje.org/ (accessed 6 Aug 2015).

16. Drazen JM, Van Der Weyden MB, Sahni P, et al. Uniform Format for Disclosure of Competing Interests in ICMJE Journals. Ann Intern Med 2010;152:125-6.

17. International Committee of Medical Journal Editors. Recommendations for the Conduct, Reporting, Editing and Publication of Scholarly Work in Medical Journals. http://www.icmje. org/ (accessed 6 Aug 2015).

18. Wager $\mathrm{E}$. The committee on publication ethics flowcharts. Chest 2010;137:221-3.

19. Japanese-language version of the ICMJE COI form. In processing, to be added to the existing http://www.ronbun.jp (accessed 21 Aug 2015).

20. Fontanarosa PB, Flanagin A, DeAngelis CD. Implementation of the ICMJE form for reporting potential conflicts of interest. JAMA 2010;304:1496. 